\title{
Performance and Area Scaling Benefits of FD-SOI Technology for 6-T SRAM Cells at the 22-nm Node
}

Changhwan Shin, Student Member, IEEE, Min Hee Cho, Yasumasa Tsukamoto, Bich-Yen Nguyen, Carlos Mazuré, Borivoje Nikolić, Senior Member, IEEE, and Tsu-Jae King Liu, Fellow, IEEE

\begin{abstract}
The performance and threshold voltage variability of fully depleted silicon-on-insulator (FD-SOI) MOSFETs are compared against those of conventional bulk MOSFETs via 3-D device simulation with atomistic doping profiles. Compact (analytical) modeling is then used to estimate six-transistor SRAM cell performance metrics (i.e., read and write margins, and read current) at the $22 \mathrm{~nm}$ CMOS technology node. The dependences of these metrics on cell ratio, pull-up ratio, and operating voltage are analyzed for FD-SOI versus bulk SRAM cells. Iso-area and iso-yield comparisons are then made to determine the yield and cell-area benefits of FD-SOI technology, respectively. Finally, the minimum operating voltages $\left(V_{\min }\right)$ required for FD-SOI and bulk SRAM cells to meet the six-sigma yield requirement are compared.
\end{abstract}

Index Terms-CMOS, MOSFET, silicon-on-insulator (SOI), SRAM, variability.

\section{INTRODUCTION}

I NCREASING variation in transistor performance with gatelength $\left(L_{\mathrm{GATE}}\right)$ scaling is a major challenge for continued bulk CMOS technology advancement [1]. The primary causes for random variations in transistor threshold voltage $\left(V_{\mathrm{TH}}\right)$ are gate line-edge roughness (LER) and random dopant fluctuations (RDFs) [2]. A lightly doped (fully depleted, FD) siliconon-insulator (SOI) MOSFET structure with a very thin $(\sim 10 \mathrm{~nm}$ thick) buried oxide (BOX) layer and a heavily doped substrate ("ground plane") has been shown to be effective for reducing the impact of parameter variations and RDF due to its excellent electrostatic integrity and the elimination of channel doping [3]. Recently, functional SRAM cells were demonstrated using such FD-SOI devices, for the $32 \mathrm{~nm}$ technology node and beyond [4]. Furthermore, thin-BOX FD-SOI MOSFET technology has been projected to provide for improved SRAM yield as compared to

Manuscript received August 26, 2009; revised March 1, 2010; accepted March 5, 2010. Date of publication April 15, 2010; date of current version May 19, 2010. This work was supported in part by Soitec and in part by the Center for Circuit and System Solutions (C2S2) Focus Center, which is one of five research centers funded through the Focus Center Research Program, a Semiconductor Research Corporation program. The work of C. Shin was supported by the Korea Foundation for Advanced Studies. The review of this paper was arranged by Editor H. S. Momose.

C. Shin, M. H. Cho, B. Nikolić, and T.-J. K. Liu are with the Department of Electrical Engineering and Computer Sciences, University of California, Berkeley, CA 94720 USA (e-mail: shinch@eecs.berkeley.edu).

Y. Tsukamoto is with the Department of Electrical Engineering and Computer Sciences, University of California, Berkeley, CA 94720 USA. He is also with the Renesas Technology Corporation, Tokyo 187-8588, Japan.

B.-Y. Nguyen and C. Mazuré are with Soitec, Austin, TX 78746 USA (e-mail: Bich-yen.nguyen@soitecusa.com).

Color versions of one or more of the figures in this paper are available online at http://ieeexplore.ieee.org.

Digital Object Identifier 10.1109/TED.2010.2046070

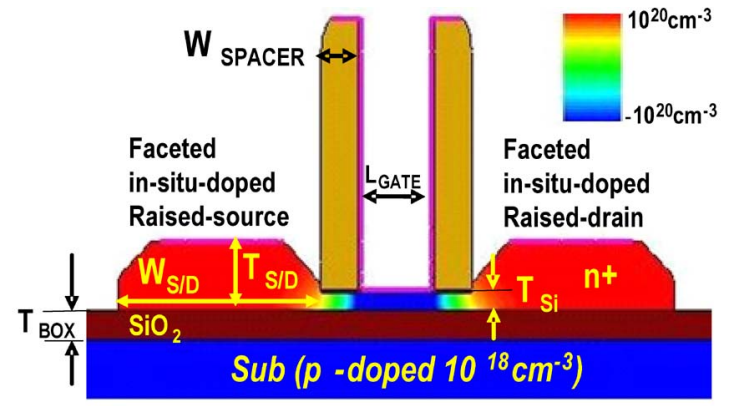

(a)

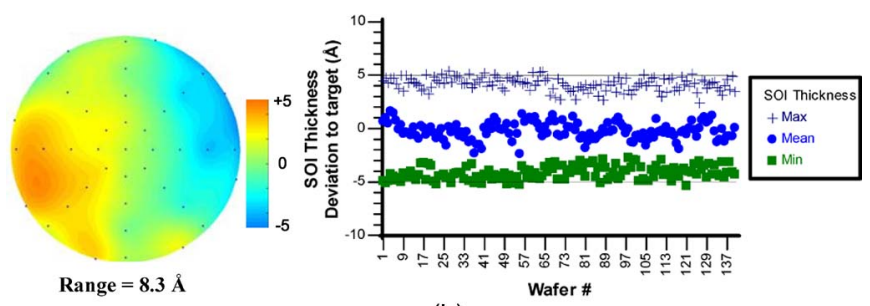

(b)

Fig. 1. (a) Cross-sectional view of the simulated thin-BOX FD-SOI MOSFET structure. The gate electrode is a thin metal layer with a specified work function. (b) Experimental data (courtesy of Soitec) for SOI layer thickness $\left(T_{\mathrm{Si}}\right)$ variation across a wafer (left) and from wafer to wafer (right). The peak-topeak variation is less than $1 \mathrm{~nm}$.

SOI FinFET technology at the $22 \mathrm{~nm}$ technology node [5]. In this paper, which follows [6], the potential advantages of thinBOX FD-SOI technology versus bulk CMOS technology with regard to six-transistor (6-T) SRAM cell performance and yield are assessed in detail for the $22 \mathrm{~nm}$ technology node.

\section{Thin-BOX FD-SOI TECHNOLOGY}

\section{A. MOSFET Design Optimization}

The thin-BOX FD-SOI CMOSFET designs were optimized via 3 -D process and device simulations with advanced physical models including the density-gradient and drift-diffusion transport models [7] and the phenomenological van Dort quantum correction model to account for energy quantization in the channel region. Physical and operating parameters (e.g., gate length, gate oxide thickness, and supply voltage) were taken from the International Technology Roadmap for Semiconductors for low-operating-power (LOP) technology at the 22-nm node [8]. The width of the gate-sidewall spacers $\left(W_{\text {spacer }}\right)$ is constrained by the gate-to-contact spacing design rule for the 6-T SRAM cell and was selected to be $15 \mathrm{~nm}$ based on [10] and in consideration of the design optimization guidelines in [9]. Fig. 1(a) shows a cross-sectional view of the simulated 
TABLE I

Optimized Thin-BOX FD-SOI AND BUlK (UNIFORM CHANNEL DOPING $\sim 10^{18} \mathrm{~cm}^{-3}$ ) MOSFET Design PARAMETERS FOR $V_{\text {DD }}=0.9 \mathrm{~V}$

\begin{tabular}{|c|c|c|c|c|}
\hline \multirow[b]{2}{*}{ Parameter } & \multicolumn{2}{|c|}{ FD-SOI } & \multicolumn{2}{|c|}{ Bulk } \\
\hline & N-type & P-type & N-type & P-type \\
\hline $\mathbf{L}_{\text {GATE }}$ & $25 \mathrm{~nm}$ & $25 \mathrm{~nm}$ & $25 \mathrm{~nm}$ & $25 \mathrm{~nm}$ \\
\hline $\mathbf{W}_{\text {SPACER }}$ & $15 \mathrm{~nm}$ & $15 \mathrm{~nm}$ & $15 \mathrm{~nm}$ & $15 \mathrm{~nm}$ \\
\hline$T_{\text {ox }}$ & $1 \mathrm{~nm}$ & $1 \mathrm{~nm}$ & $1 \mathrm{~nm}$ & $1 \mathrm{~nm}$ \\
\hline $\mathbf{T}_{\text {BOX }}$ & $10 \mathrm{~nm}$ & $10 \mathrm{~nm}$ & NA & NA \\
\hline $\mathbf{T}_{\mathbf{S i}}$ & $6 \mathrm{~nm}$ & $6 \mathrm{~nm}$ & NA & NA \\
\hline$X_{\mathrm{J}, \mathrm{EXT}}$ & NA & NA & $10 \mathrm{~nm}$ & $10 \mathrm{~nm}$ \\
\hline$x_{J, S / D}$ & NA & NA & $22 \mathrm{~nm}$ & $22 \mathrm{~nm}$ \\
\hline$\Phi_{M}$ & $4.45 \mathrm{eV}$ & $4.85 \mathrm{eV}$ & $4.05 \mathrm{eV}$ & $5.20 \mathrm{eV}$ \\
\hline $\mathrm{T}_{\mathrm{S} / \mathrm{D}}$ & $22.6 \mathrm{~nm}$ & $22.6 \mathrm{~nm}$ & NA & NA \\
\hline$w_{S / D}$ & $72 \mathrm{~nm}$ & $72 \mathrm{~nm}$ & $72 \mathrm{~nm}$ & $72 \mathrm{~nm}$ \\
\hline
\end{tabular}

n-channel MOSFET structure. An implantation-free process is used as follows in order to avoid dopant-atom straggle and defects in the thin body region to minimize RDF-induced variations [10]: faceted raised-source/drain regions are formed by a low-temperature zero-silicon-loss epitaxial growth process with in situ doping $\left(10^{20} \mathrm{~cm}^{-3}\right)$ to reduce series resistance with minimal increase in gate-sidewall capacitance; then the lightly doped source/drain extension regions are formed by diffusion of dopant atoms from the raised-source/drain regions. The electrical channel length ( $L_{\mathrm{eff}}$, defined as the distance between the lateral positions where the source and drain doping concentrations fall to $2 \times 10^{19} \mathrm{~cm}^{-3}$ [11]) is tuned by adjusting the duration of the dopant-diffusion anneal step to achieve the maximum drive current for a gate voltage swing and drain bias equal to the supply voltage $V_{\mathrm{DD}}(0.9 \mathrm{~V})$. The gate work function values were then selected to adjust the nominal $V_{\mathrm{TH}}$ values in order to meet the OFF-state leakage current $\left(I_{\mathrm{OFF}}\right)$ specification, i.e., $3 \mathrm{nA} / \mu \mathrm{m}$. The optimized device parameters for the FD-SOI devices are summarized in Table I.

For comparison, bulk CMOSFETs meeting the same $I_{\mathrm{OFF}}$ specification also were designed (Table I). Fig. 2 compares the transfer characteristics $\left(I_{\mathrm{DS}}\right.$ versus $V_{\mathrm{GS}}$ ) for the optimized n-channel FD-SOI and bulk MOSFET structures. The FD-SOI device exhibits a steeper subthreshold slope due to negligible depletion capacitance and higher drive current due to higher carrier mobility. A summary comparison of device performance parameters is given in Table II. Both the FD-SOI and bulk MOSFET structures meet the general specification for drain-induced barrier lowering (DIBL) to be no greater than $100 \mathrm{mV} / \mathrm{V}$. (DIBL for the bulk devices is comparable to that of the FD-SOI device because of the very shallow source/drain extension depths.)

An analytical $I-V$ model for the short-channel MOSFET [see (1)] was fit to the simulated current-versus-voltage characteristics and then used to compute SRAM metrics such as read static noise margin (SNM) [12], [14], write current $\left(I_{w}\right)$ (a)

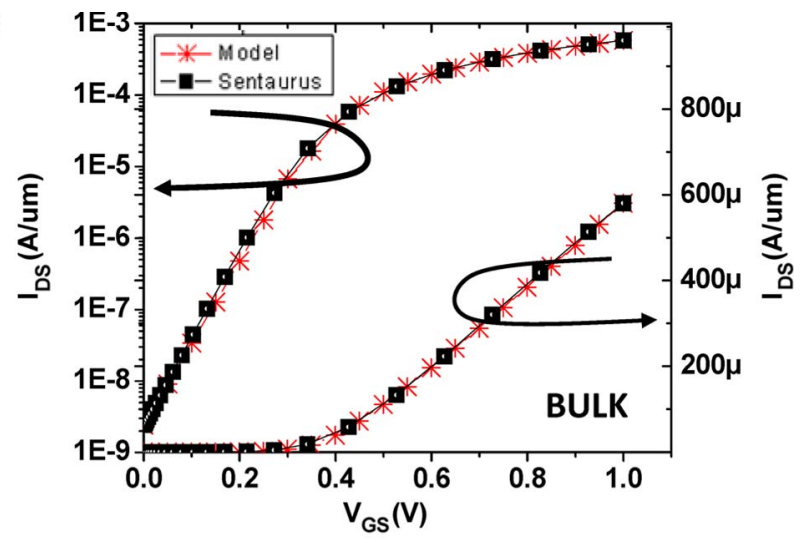

(b)

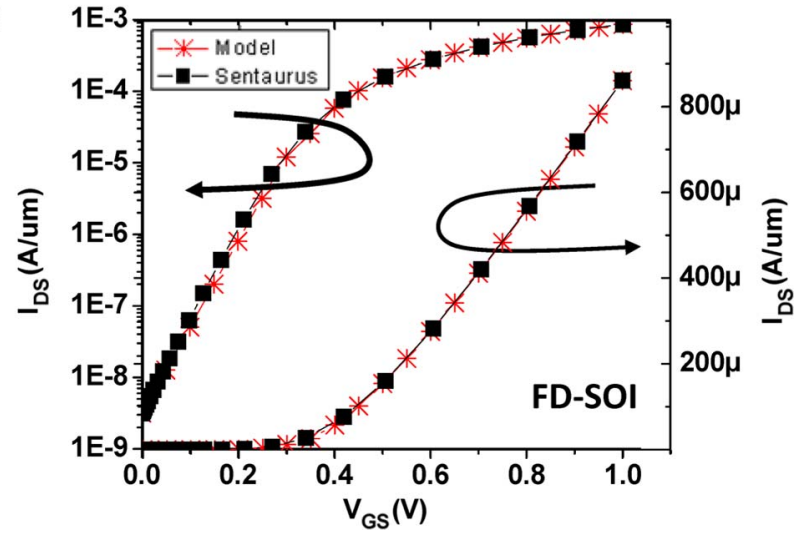

Fig. 2. Transfer characteristics. (a) Bulk MOSFET. (b) FD-SOI MOSFET. The analytical $I-V$ model is fit (to within $5 \%$ ) to the simulated characteristics, using the current values at 6 points: $\left(V_{\mathrm{GS}}, V_{\mathrm{DS}}\right)=$ $\{(1.0,1.0),(1.0,0.5),(1.0,0.1),(0.5,1.0),(0.5,0.1),(0.0,1.0)\}$.

[13], [14], and read current, following the methodology described in [22]. Five simulated $I-V$ targets corresponding to the operating biases most critical for modeling SRAM metrics, i.e., $\left(V_{\mathrm{GS}}, V_{\mathrm{DS}}\right)=(1.0 \mathrm{~V}, 0.1 \mathrm{~V}),(1.0 \mathrm{~V}, 1.0 \mathrm{~V}),(0.5 \mathrm{~V}$, $1.0 \mathrm{~V}),(1.0 \mathrm{~V}, 0.5 \mathrm{~V})$, and $(0.0 \mathrm{~V}, 1.0 \mathrm{~V})$, in addition to 
TABLE II

Comparison of Device Performance Parameters for $V_{\mathrm{DD}}=0.9 \mathrm{~V}$

\begin{tabular}{|c|c|c|c|c|}
\hline \multirow{2}{*}{$\mathrm{V}_{\mathrm{DD}}=0.9 \mathrm{~V}$} & \multicolumn{2}{|c|}{ FD-SOI } & \multicolumn{2}{c|}{ Bulk } \\
\cline { 2 - 5 } & N-type & P-type & N-type & P-type \\
\hline $\mathrm{I}_{\mathrm{ON}}[\mu \mathrm{A} / \mu \mathrm{m}]$ & 704 & 417 & 483 & 301 \\
\hline $\mathrm{I}_{\mathrm{OFF}}[\mathrm{nA} / \mu \mathrm{m}]$ & 3 & 3 & 3 & 3 \\
\hline SS $[\mathrm{mV} / \mathrm{dec}]$ & 75 & 83 & 81 & 89 \\
\hline $\mathrm{V}_{\mathrm{T}, \mathrm{LIN}}[\mathrm{mV}]$ & 164 & -186 & 182 & -207 \\
\hline $\mathrm{V}_{\mathrm{T}, \mathrm{SAT}}[\mathrm{mV}]$ & 118 & -124 & 134 & -142 \\
\hline DIBL $[\mathrm{mV} / \mathrm{V}]$ & 54.1 & 72.9 & 56.5 & 76.5 \\
\hline $\mathrm{L}_{\text {eff }}[\mathrm{nm}]$ & 35.6 & 30.7 & 46.1 & 40.5 \\
\hline
\end{tabular}

linear $\left(V_{\mathrm{DS}}=0.1 \mathrm{~V}\right)$ and saturation $\left(V_{\mathrm{DS}}=1.0 \mathrm{~V}\right)$ threshold voltage values, were used to fit the analytical $I-V$ model for each case of $+10 \%$ or $-10 \%$ variation in channel length $(L)$, channel width $(W)$, gate oxide thickness $\left(T_{\mathrm{ox}}\right)$ or $V_{\mathrm{TH}}$. Linear interpolation or extrapolation was then used to obtain the analytical $I-V$ curves for arbitrary variations in $L, W, T_{\text {ox }}$, and $V_{\mathrm{TH}}$, which were then used to compute the SRAM metrics. $L, W$, and $T_{\text {ox }}$ are assumed to have Gaussian distribution (with 3 -sigma corresponding to $\pm 10 \%$ ), while the standard deviation in $V_{\mathrm{TH}}$ due to random variations was determined as described in Section II-B.

\section{B. Impact of Random Variations}

The impacts of gate LER and RDF were evaluated via 3-D device and process simulations with atomistic doping profiles [7]. A scanning electron microscopy image of photoresist lines processed for the 22-nm node was sampled 100 times to provide the realistic gate electrode profiles for 3-D device simulations. Thirty kinetic Monte Carlo simulations-which account for reactions between defects and impurities as predicted by molecular dynamics-were performed for each of these gate electrode profile cases. The source/drain extensions in the bulk structure are formed by dopant ion implantation; the resultant defects result in larger $I_{\text {dsat }}$ variation for the bulk structure. In contrast, the source/drain extensions in the FD-SOI structure are formed by dopant diffusion; because implant damage is avoided, less $I_{\mathrm{dsat}}$ variation (and smaller $\sigma\left(V_{\mathrm{TH}}\right)$ ) is seen for the FD-SOI structure. The device simulation results are shown in Fig. 3. The impact of gate work function variations (WFVs) can be significant for nanometer-scale MOSFETs. Based on [15], $\sigma\left(V_{\mathrm{TH}}\right)$ due to $\mathrm{WFV}$ is estimated to be $12.4 \mathrm{mV}$ for the pull-down transistors in the 22-nm-node SRAM cell. Under the assumption that WFV is statistically independent of gate LER and $\mathrm{RDF}$ [16], the total $V_{\mathrm{TH}}$ variation is calculated as follows:

$\left.\sigma\left(V_{\mathrm{TH}}\right)\right|_{\text {Total, random }}$

$\approx \sqrt{\left.\sigma\left(V_{\mathrm{TH}}\right)^{2}\right|_{\mathrm{LER}}+\left.\sigma\left(V_{\mathrm{TH}}\right)^{2}\right|_{\mathrm{RDF}}+\left.\sigma\left(V_{\mathrm{TH}}\right)^{2}\right|_{\mathrm{WFV}}}$. (a)
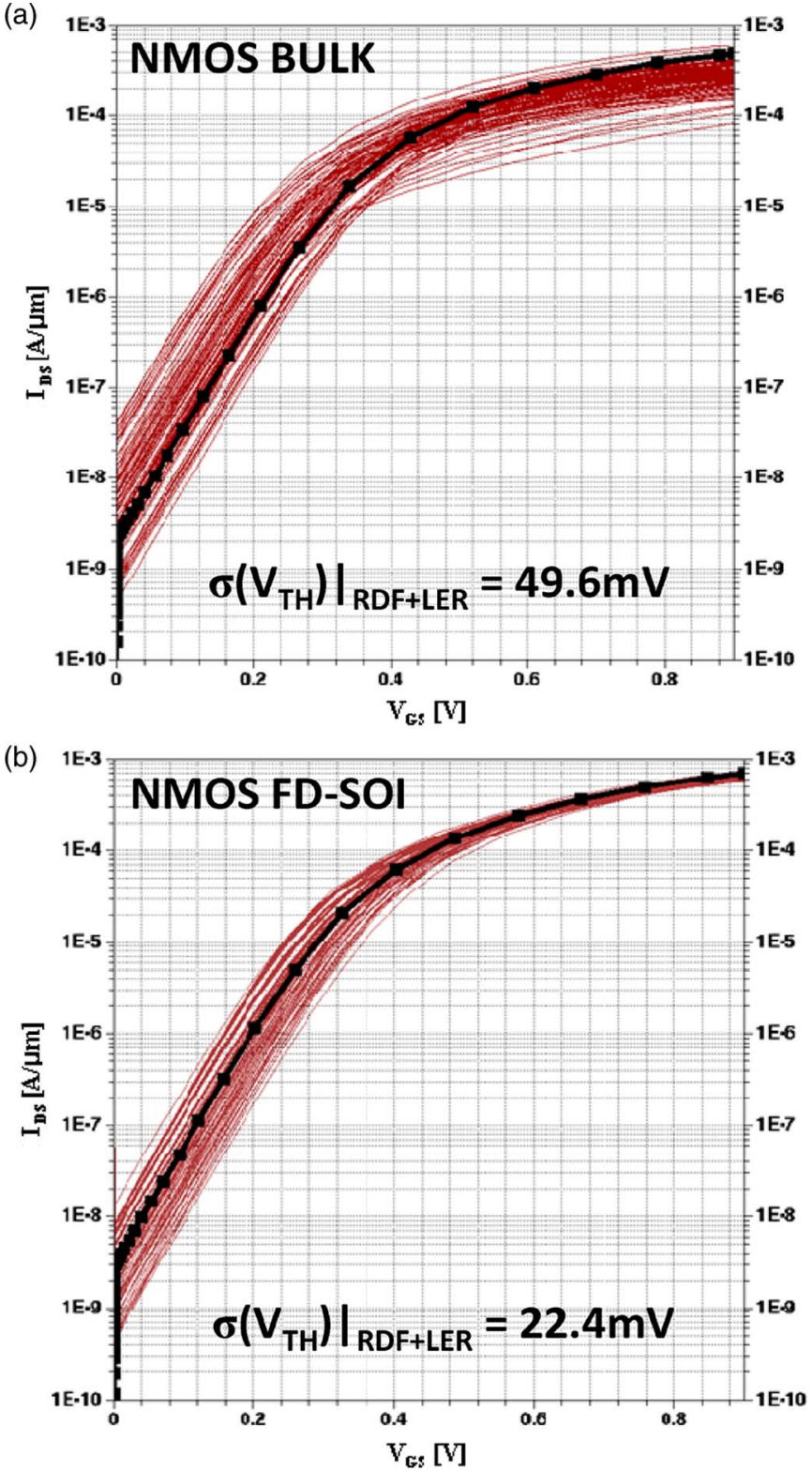

Fig. 3. Simulated transfer characteristics of the pull-down transistor for 500 cases of gate-LER and atomistic doping. (a) Bulk MOSFET (b) FD-SOI MOSFET. $V_{\mathrm{DD}}=0.9 \mathrm{~V}$. The simulated transfer characteristics for continuum doping are also shown (with thicker lines) for reference.

Due to reduced $V_{\mathrm{TH}}$ roll-off and light channel doping, the FD-SOI structure provides for a $V_{\mathrm{TH}}$ variation smaller than that of the bulk structure: $\left.\sigma\left(V_{\mathrm{TH}}\right)\right|_{\mathrm{SOI}}=26 \mathrm{mV}$ versus $\left.\sigma\left(V_{\mathrm{TH}}\right)\right|_{\mathrm{BULK}}=50 \mathrm{mV}$. It also shows less lowering of the average value of $V_{\mathrm{TH}}$ due to atomistic doping effects.

\section{SiX-Transistor SRAM CELl PERFORMANCE COMPARISON}

\section{A. Nominal Cell Design}

Based on recent publications [17]-[21], the dimensions for 22-nm-node 6-T SRAM cells were selected for this study. The cell layout parameters are summarized in Table III. Fig. 4(a) and (b) shows the butterfly plots and write-N curves, respectively, obtained using the analytical $I-V$ model. 
TABLE III

FD-SOI 6-T SRAM Cell Dimensions. A Half-Bit Cell Image Is Shown on the Left Side

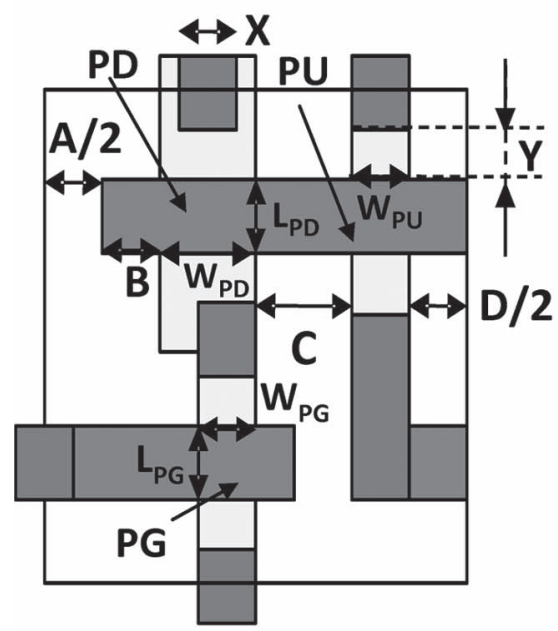

\begin{tabular}{|c|c|c|c|}
\hline \multicolumn{2}{|c|}{ Design rules } & Symbol & Size [nm] \\
\hline \multirow{5}{*}{$\begin{array}{c}\text { Cell } \\
\text { Height }\end{array}$} & PG CH length & $\mathbf{L}_{\mathbf{P G}}$ & 25 \\
\hline & PD CH length & $\mathbf{L}_{\mathrm{PD}}$ & 25 \\
\hline & CONT size & $\mathbf{X}$ & 30 \\
\hline & Gate-to-CONT & Y & 20 \\
\hline & Total & \multicolumn{2}{|c|}{190} \\
\hline \multirow{8}{*}{$\begin{array}{c}\text { Cell } \\
\text { Width }\end{array}$} & POLY-to-POLY & A & 30 \\
\hline & POLY-to-DIF ext & B & 20 \\
\hline & PD Width & $\mathbf{W}_{\mathrm{PD}}$ & 55 \\
\hline & $\mathrm{N} / \mathrm{P}$ isolation & C & 50 \\
\hline & PU width & $\mathbf{W}_{\mathrm{PU}}$ & 32 \\
\hline & DIF-DIF (min) & D & 50 \\
\hline & PG width & $\mathbf{W}_{\mathrm{PG}}$ & 35 \\
\hline & Total & \multicolumn{2}{|c|}{394} \\
\hline \multicolumn{2}{|c|}{ A SRA M cell area } & \multicolumn{2}{|c|}{$0.07486 \mu \mathrm{m}^{2}$} \\
\hline
\end{tabular}

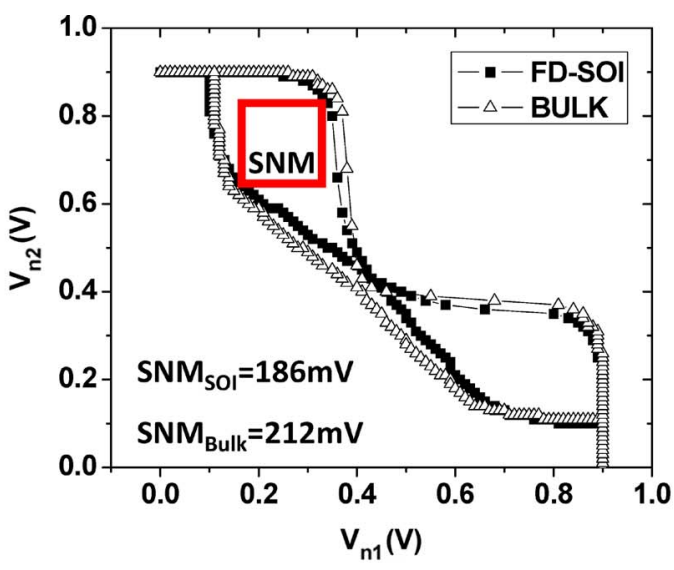

(a)

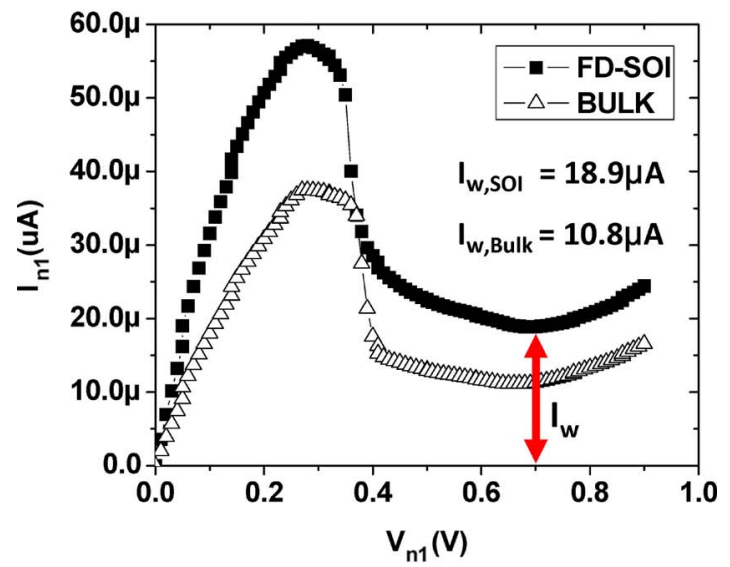

(b)

Fig. 4. Comparisons of (a) SNM and (b) write current $\left(I_{w}\right)$, for $V_{\mathrm{DD}}=$ $0.9 \mathrm{~V}$. The write-ability of the FD-SOI SRAM cell is larger by $71 \%$, but the SNM is lower by $10 \%$.

Although the FD-SOI cell has a slightly lower SNM due to its lower switching voltage, it has higher write-ability $(\sim 70 \%$ higher $\left.I_{w}\right)$ and read current $\left(\sim 60 \%\right.$ higher $\left.I_{\text {read }}\right)$. Thus, the FD-SOI cell offers a better tradeoff between read stability and write-ability, as compared to the bulk cell.
B. Dependency of SRAM Performance Metrics on Cell Ratio, Pull-Up Ratio, and $V_{\mathrm{DD}}$

For a fixed cell area, there is room to adjust the width of the pass-gate transistors $\left(W_{\mathrm{PG}}\right)$ in order to optimize the tradeoff between the various SRAM performance metrics (i.e., SNM, $I_{w}$, and $\left.I_{\text {read }}\right)$. This is because the SNM increases with increasing cell $(\beta)$ ratio $\left(=W_{\mathrm{PD}} / W_{\mathrm{PG}}\right)$, which decreases with increasing $W_{\mathrm{PG}} ; I_{w}$ increases with decreasing pull-up $(\alpha)$ ratio $\left(=W_{\mathrm{PU}} / W_{\mathrm{PG}}\right)$, which decreases with increasing $W_{\mathrm{PG}}$; and $I_{\text {read }}$ increases directly with $W_{\mathrm{PG}}$. Fig. 5(a)-(c) shows the dependences of SNM, $I_{w}$, and $I_{\text {read }}$ on cell ratio, pull-up ratio, and $W_{\mathrm{PG}}$, respectively. The improved tradeoff between read stability and write-ability offered by the FD-SOI cell can be evaluated graphically using these figures. For example, the FD-SOI can achieve comparable SNM $(\sim 212 \mathrm{mV})$ as the bulk cell if $W_{\mathrm{PG}}$ is decreased to $27.2 \mathrm{~nm}$ (so that cell ratio $=W_{\mathrm{PD}} / W_{\mathrm{PG}}=55 \mathrm{~nm} / 27.2 \mathrm{~nm}=2.02$, and pull-up ratio $\left.=W_{\mathrm{PU}} / W_{\mathrm{PG}}=32 \mathrm{~nm} / 27.2 \mathrm{~nm}=1.18\right)$, in which case $I_{w}(\sim 12.4 \mu \mathrm{A})$ is still $15 \%$ higher than that for the bulk cell $(\sim 10.8 \mu \mathrm{A})$, and $I_{\text {read }}(\sim 15.5 \mu \mathrm{A})$ is still $34 \%$ higher than that for the bulk cell $(11.6 \mu \mathrm{A})$. Fig. 6 compares the dependences of SNM, $I_{w}$, and $I_{\text {read }}$ on $V_{\mathrm{DD}}$ for this case (in which $W_{\mathrm{PG}}$ is reduced to $27.2 \mathrm{~nm}$ for the FD-SOI cell). The FD-SOI benefit of improved write-ability $\left(I_{w}\right)$ and speed $\left(I_{\text {read }}\right)$ for comparable read stability $(\mathrm{SNM})$ is retained as $V_{\mathrm{DD}}$ is reduced.

\section{Yield-AwARE SRAM CELl DESIGN}

In Section III, the FD-SOI cell was shown to offer improved tradeoff between the nominal values of SNM and $I_{w}$ for a fixed cell area. In this section, the corresponding improvement in cell yield is evaluated using the concept of cell sigma, defined as the minimum amount of variation for read/write failure [22]. Assuming that the metric (SNM or $I_{w}$ ) has a Gaussian distribution, this is simply the mean divided by the standard deviation. If a metric " $f$ " is subject to small independent parameter variations " $x_{i}$ " in a range such that " $f$ " can be approximated as a linear 


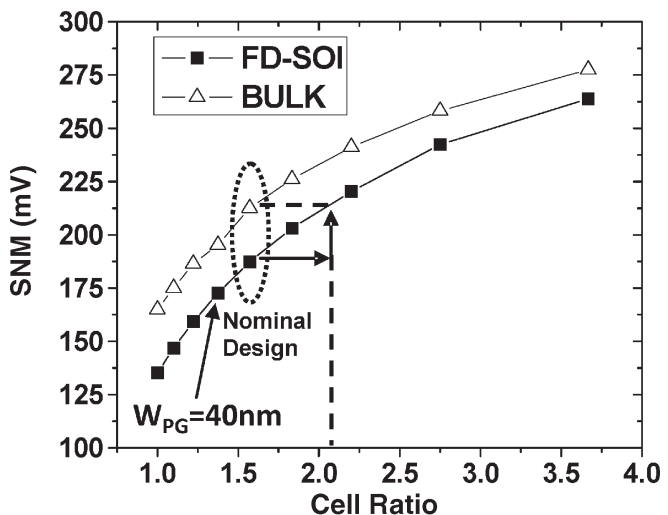

(a)

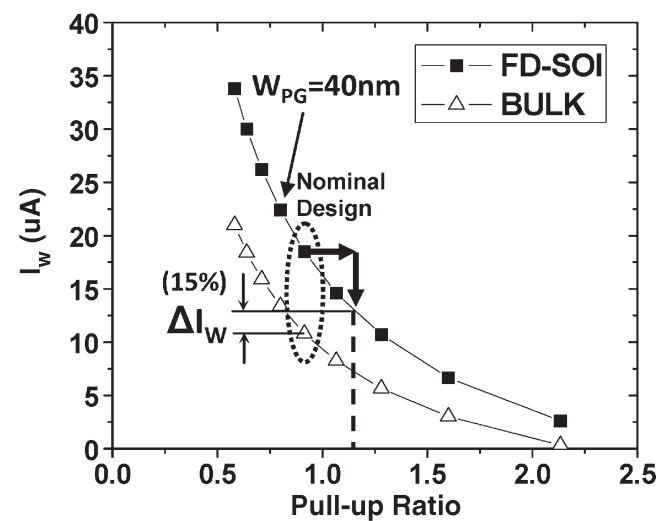

(b)

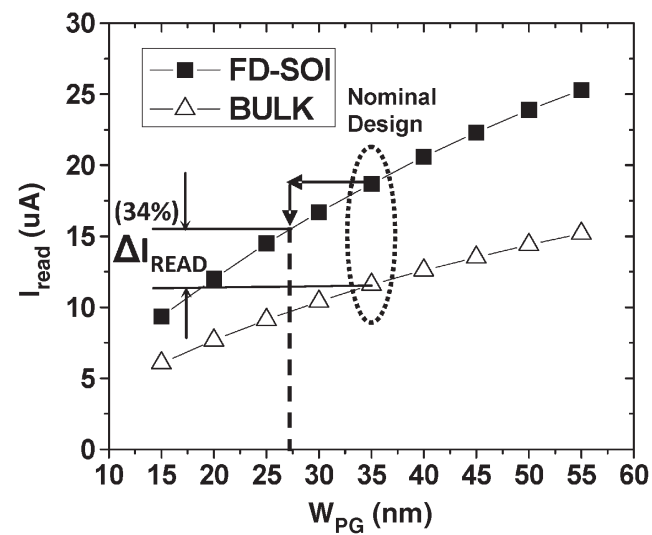

(c)

Fig. 5. Comparison of cell performance metrics for FD-SOI versus bulk 6-T SRAM cells: (a) SNM; (b) $I_{w}$; and (c) $I_{\text {read }}$. (The curves are each obtained by adjusting the value of $W_{\mathrm{PG}}$.)

function of " $x_{i}$," then the distribution of the metric is Gaussian, according to the Central Limit Theorem. The cell sigma is given by

$$
\text { cell sigma }=\frac{f(0)}{\sqrt{\sum_{i}\left(\frac{\partial f}{\partial x_{i}}\right)^{2} \sigma_{x_{i}}^{2}}} .
$$

It should be noted that SNM and $I_{w}$ each exhibit a linear response to small variations in $x_{i}$. Although their sensitivities can become nonlinear for large variations (beyond several $\sigma_{x_{i}}$ ), the most probable combination of variations in $L, W, T_{\text {ox }}$ and $V_{\mathrm{TH}}$ does not exceed $\sim 4 \sigma$ variation in a single parameter.

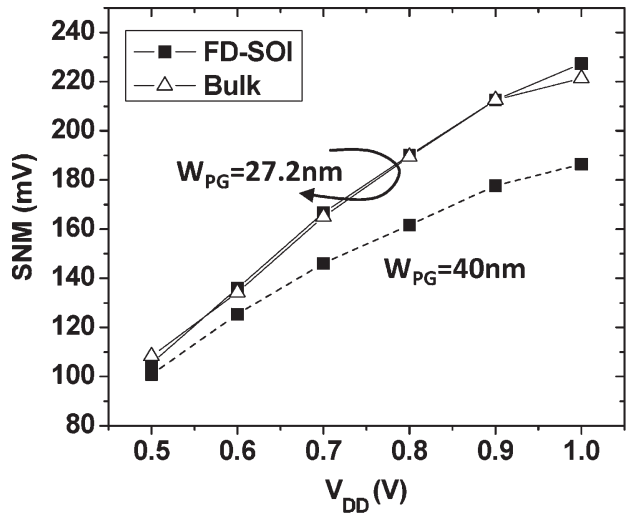

(a)

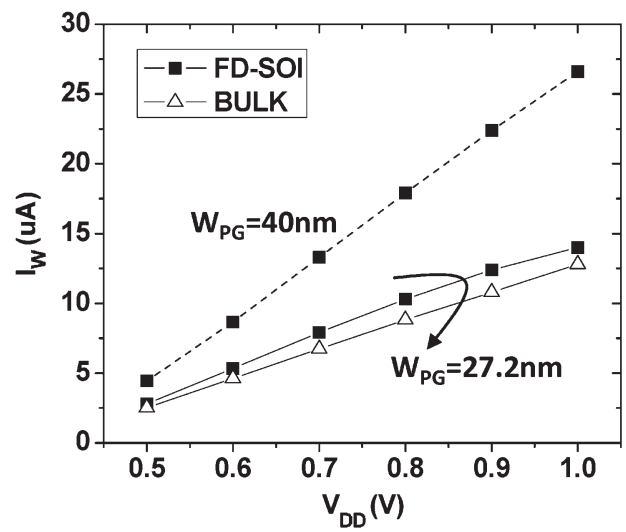

(b)

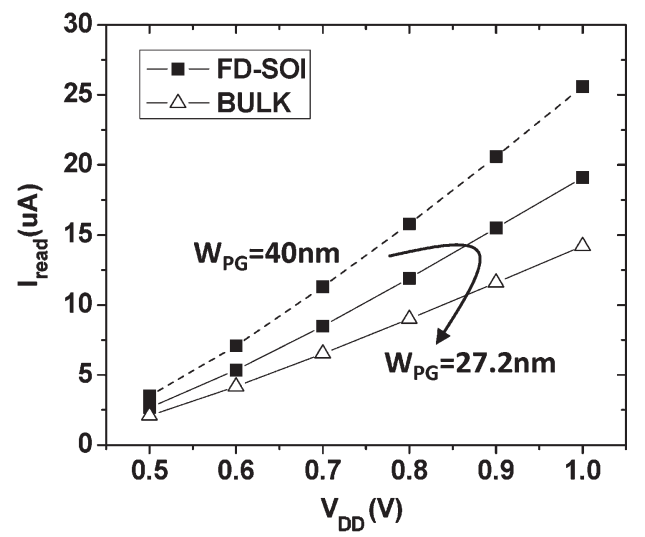

(c)

Fig. 6. Impact of $V_{\mathrm{DD}}$ scaling on 6-T SRAM cell performance metrics.

Thus, this method of estimating SRAM yield is reasonably accurate [22].

As explained above, random variations due to gate LER and $\mathrm{RDF}$, as well as global (Gaussian) variations due to processinduced variations $( \pm 10 \%)$ in gate length, channel width, gate oxide thickness, and body thickness [Fig. 1(b)] are considered.

\section{A. Iso-Area Comparison}

In the future, six-sigma $(6 \sigma)$ yield or larger will be required for large SRAM arrays to be functional. Fig. 7 shows the tradeoff between $I_{w}$ yield and SNM yield for FD-SOI and bulk cells, for $V_{\mathrm{DD}}=0.9 \mathrm{~V}$. ( $W_{\mathrm{PG}}$ is varied along the curves.) In order for a cell design to meet the $6 \sigma$ yield requirement, both SNM and $I_{w}$ must be able to tolerate at least $6 \sigma$ variation. The FD-SOI 


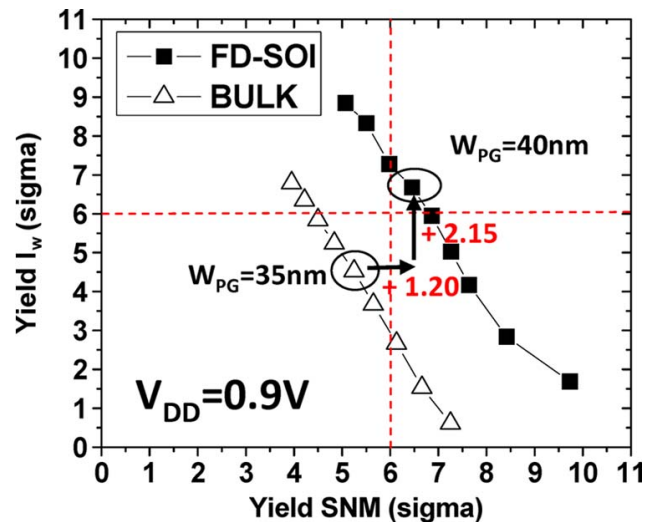

Fig. 7. Yield of $I_{w}$ versus yield of SNM. The optimal design points for bulk and FD-SOI cells are indicated (corresponding to $W_{\mathrm{PG}}=35 \mathrm{~nm}$ for the optimal bulk cell and $W_{\mathrm{PG}}=40 \mathrm{~nm}$ for the optimal FD-SOI cell).

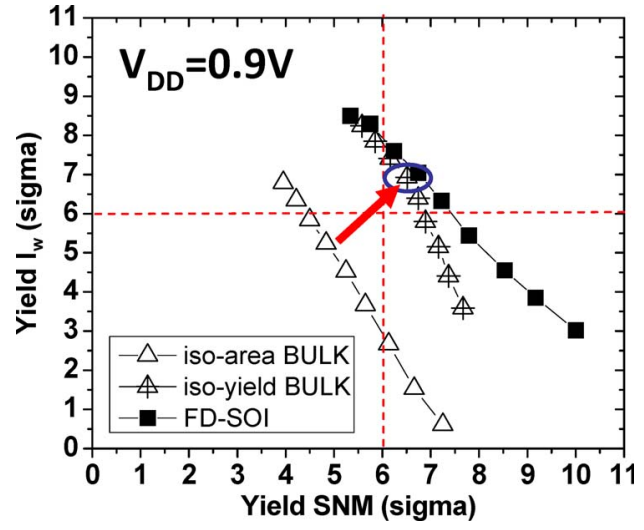

Fig. 8. By upsizing the bulk cell, yield that is comparable to that of the FD-SOI cell can be achieved. However, the tradeoff between yield of $I_{w}$ and yield of SNM is more severe for the bulk cell due to lower drive current and larger random $V_{\mathrm{TH}}$ variation.

cell can satisfy the $6 \sigma$ yield requirement and achieves maximum cell sigma with $W_{\mathrm{PG}}=40 \mathrm{~nm}$. Approximately $10 \mathrm{~nm}$ variation in $W_{\mathrm{PG}}$ can be tolerated at this design point. In contrast, the bulk cell cannot satisfy the $6 \sigma$ yield requirement. The optimal bulk cell design corresponds to $W_{\mathrm{PG}}=35 \mathrm{~nm}$ and has $\sim 1.2 \sigma$ worse SNM yield and $\sim 2.2 \sigma$ worse $I_{w}$ yield than the FD-SOI cell.

\section{B. Iso-Yield Comparison}

In order for the bulk cell to achieve $>6 \sigma$ yield, comparable to that of the optimized FD-SOI cell (with $W_{\mathrm{PG}}=40 \mathrm{~nm}$ ), the pull-down and pull-up transistor widths must be increased to $W_{\mathrm{PD}}=95 \mathrm{~nm}$ and $W_{\mathrm{PU}}=50 \mathrm{~nm}$, respectively, so that the cell area is increased by $\sim 30 \%$ (from $\sim 0.075 \mu \mathrm{m}^{2}$ to $\sim 0.1 \mu \mathrm{m}^{2}$ ). In other words, the area savings offered by the FD-SOI cell is $\sim 25 \%$. The resultant $I_{w}$ yield versus SNM yield curve is plotted in Fig. 8, along with the curves from Fig. 7. The spotlighted design point corresponds to $W_{\mathrm{PG}}=65 \mathrm{~nm}$.

\section{Minimum Operating Voltage $\left(V_{\min }\right)$}

By plotting $I_{w}$ yield versus SNM yield for various values of $V_{\mathrm{DD}}, V_{\min }$ can be estimated. Fig. 9(a) and (b) shows the impact of $V_{\mathrm{DD}}$ reduction on yield for the bulk and FD-SOI

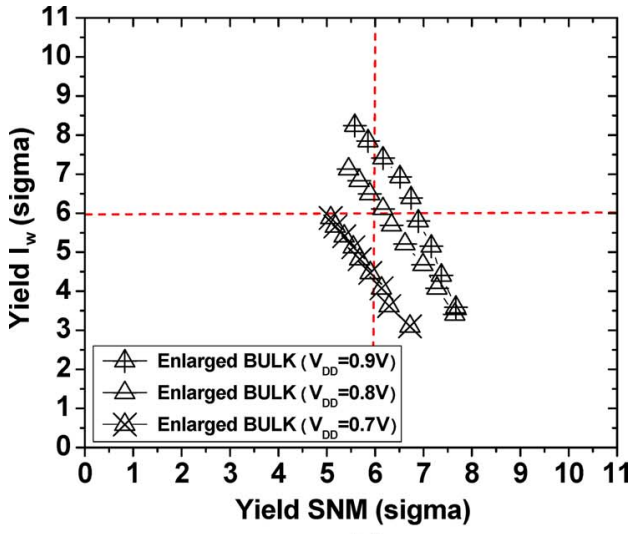

(a)

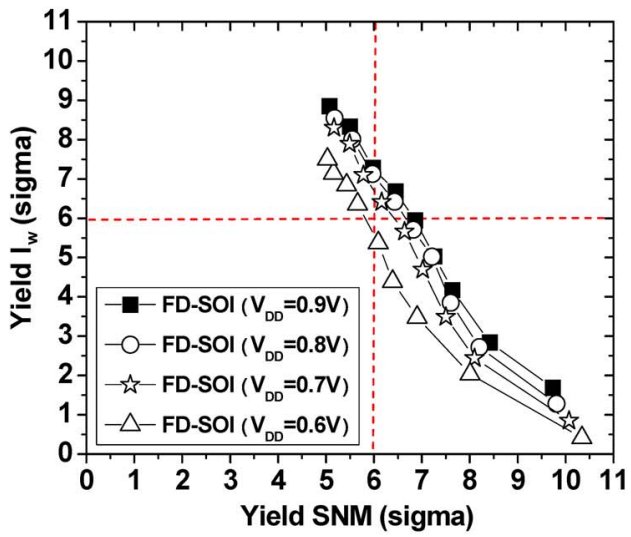

(b)

Fig. 9. Dependence of yield on $V_{\mathrm{DD}}$ : (a) upsized bulk cell and (b) FD-SOI cell. At $V_{\mathrm{DD}} \sim 0.8 \mathrm{~V}$, the bulk cell cannot satisfy the $6 \sigma$ requirement, in contrast to the FD-SOI cell. $V_{\min }$ is significantly lower, i.e., $\sim 0.6 \mathrm{~V}$, for the FD-SOI cell.

TABLE IV

Summary of SRAM Cell Performance Metrics For FD-SOI AND ENLARGED BULK SRAM CELLS

\begin{tabular}{|c|c|c|c|c|}
\hline & \multicolumn{2}{|c|}{ FD-SOI SRAM cell } & \multicolumn{2}{c|}{$\begin{array}{c}\text { Enlarged Bulk } \\
\text { SRAM cell }\end{array}$} \\
\hline Supply voltage & $\mathrm{V}_{\min }(=0.6 \mathrm{~V})$ & $\mathrm{V}_{\mathrm{DD}}(=0.9 \mathrm{~V})$ & $\mathrm{V}_{\min }(=0.8 \mathrm{~V})$ & $\mathrm{V}_{\mathrm{DD}}(=0.9 \mathrm{~V})$ \\
\hline Cell area $\left[\mu \mathrm{m}^{2}\right]$ & 0.075 & 0.075 & 0.097 & 0.097 \\
\hline $\mathrm{SNM}[\mathrm{mV}]$ & 123 & 178 & 182 & 200 \\
\hline $\mathrm{I}_{\mathrm{W}}[\mu \mathrm{A}]$ & 8.2 & 22.4 & 17.6 & 21.8 \\
\hline $\mathrm{I}_{\text {read }}[\mu \mathrm{A}]$ & 7.0 & 20.6 & 16.3 & 20.9 \\
\hline $\begin{array}{c}\mathrm{W}_{\mathrm{PG}}[\mathrm{nm}] \text { for } \\
\text { maximum yield }\end{array}$ & 38 & 40 & 65 & 65 \\
\hline
\end{tabular}

cells, respectively. At $V_{\mathrm{DD}} \sim 0.6 \mathrm{~V}$, the FD-SOI cell can no longer meet the $6 \sigma$ criterion, i.e., $V_{\min } \sim 0.6 \mathrm{~V}$. At $V_{\mathrm{DD}} \sim$ $0.8 \mathrm{~V}$, the increased-area bulk cell can no longer meet the $6 \sigma$ criterion, i.e., $V_{\min } \sim 0.8 \mathrm{~V}$. The FD-SOI cell achieves lower $V_{\min }$ because it provides for higher transistor drive current and reduced variability. Table IV summarizes the performance metrics of the FD-SOI and enlarged bulk SRAM cells at $V_{\min }$ and nominal $V_{\mathrm{DD}}$. 


\section{CONCLUSION}

Thin-BOX FD-SOI and bulk CMOSFET designs were optimized via 3-D process and device simulations for LOP CMOS technology at the 22-nm node. For the same $I_{\mathrm{OFF}}$, the FD-SOI device achieves higher drive current and reduced random $V_{\mathrm{TH}}$ variation. Using an analytical model fit to the simulated $I-V$ characteristics for the optimized device designs, 6-T SRAM cell performance metrics (i.e., SNM, $I_{w}$, and $I_{\text {read }}$ ) were estimated. For a fixed cell area, FD-SOI technology was found to provide for improved SNM yield (by $1.2 \sigma$ ) and $I_{w}$ yield (by $2.2 \sigma$ ). For fixed yield, the FD-SOI cell provides an area savings of $\sim 25 \%$. The minimum operating voltage for $6 \sigma$ yield $\left(V_{\min }\right)$ is $\sim 0.6 \mathrm{~V}$ for the FD-SOI cell, whereas it is $>0.8 \mathrm{~V}$ for the bulk cell. Thus, thin-BOX FD-SOI technology can facilitate the scaling of 6-T SRAM cell area and operating voltage.

\section{APPENDIX}

The analytical MOSFET $I-V$ model used to estimate SRAM performance metrics in this work is

$$
\begin{aligned}
I_{\mathrm{DS}}= & \mu_{s} C_{\mathrm{ox}} \frac{W}{2 m L} \frac{\left(V_{\mathrm{GS}}-V_{\mathrm{TH}}\right)^{2}}{1+\frac{V_{\mathrm{GS}}-V_{\mathrm{TH}}}{E_{\mathrm{sat}} L}} \quad V_{\mathrm{DS}} \geq \frac{V_{\mathrm{GS}}-V_{\mathrm{TH}}}{m} \\
& \times\left(1+\lambda V_{\mathrm{DS}}\right)+I_{\mathrm{sub}}\left(1-e^{\frac{V_{\mathrm{DS}}}{V_{\mathrm{TH}}}}\right) \\
& \text { if } V_{\mathrm{GS}}>V_{\mathrm{TH}} \quad V_{\mathrm{DS}}<\frac{V_{\mathrm{GS}}-V_{\mathrm{TH}}}{m} \\
= & \mu_{l} C_{\mathrm{ox}} \frac{W}{L} \frac{V_{\mathrm{DS}}\left(V_{\mathrm{GS}}-V_{\mathrm{TH}}-\frac{m V_{\mathrm{DS}}}{V_{0}}\right)^{2}}{1+\frac{V_{\mathrm{GS}}-V_{\mathrm{TH}}}{E_{\mathrm{sat}} L}} \\
& \times\left(1+\lambda V_{\mathrm{DS}}\right)+I_{\mathrm{Sub}}\left(1-e^{\frac{V_{\mathrm{DS}}}{V_{\mathrm{TH}}}}\right) \\
& \text { if } V_{\mathrm{GS}}>V_{\mathrm{TH}} \quad \text { if } V_{\mathrm{GS}} \leq V_{\mathrm{TH}} \quad(1) \\
= & I_{\mathrm{sub}}\left(1-e^{\frac{V_{\mathrm{DS}}}{V_{\mathrm{TH}}}}\right) e^{\frac{V_{\mathrm{GS}}-V_{\mathrm{TH}}}{S}}
\end{aligned}
$$

where $C_{\mathrm{ox}}$ is the gate oxide capacitance per area, $L$ is the gate length, $W$ is the device width, $I_{\text {sub }}$ is the current level corresponding to $V_{\mathrm{TH}}, S$ is the subthreshold swing, and $V_{\mathrm{TH}}$ is the threshold voltage, which is dependent on drain bias $\left(V_{\mathrm{TH}}=\right.$ $\left.V_{\mathrm{T} 0}-\mathrm{DIBL} * V_{\mathrm{DS}}\right) . \mu_{l}$ and $\mu_{s}$ are the carrier mobility values in the linear and saturation regimes of operation, respectively. $V_{0}$ is defined as $1 /\left(1-\mu_{s} / 2 \mu_{l}\right)$. $E_{\text {sat }}$ is the saturation electric field, which determines the amount of velocity saturation. $m$ is a fitting parameter. As experimentally verified in [22], this model accurately captures bulk MOSFET short-channel effects and operation in the subthreshold, linear, and saturation regimes. So long as the analytical $I-V$ model can be well fit to the simulated (or measured) $I-V$ data for FD-SOI devices, it can accurately represent their behavior as well.

\section{ACKNOWLEDGMENT}

The authors would like to thank Dr. Z. Guo and Dr. D. Lee for the helpful discussions.

\section{REFERENCES}

[1] K. J. Kuhn, "Reducing variation in advanced logic technologies: Approaches to process and design for manufacturability of nanoscale CMOS," in IEDM Tech. Dig., Dec. 2007, pp. 471-474.

[2] A. Asenov, "Simulation of statistical variability in nano MOSFETs," in VLSI Symp. Tech. Dig., Jun. 2007, pp. 86-87.

[3] T. Ohtou, N. Sugii, and T. Hiramoto, "Impact of parameter variations and random dopant fluctuations on short-channel fully depleted SOI MOSFETs with extremely thin BOX," IEEE Electron Device Lett., vol. 28, no. 8, pp. 740-742, Aug. 2007.

[4] C. Fenouillet-Beranger, S. Denorme, P. Perreau, C. Buj, O. Faynot, F. Andrieu, L. Tosti, S. Barnola, T. Salvetat, X. Garros, M. Casse, F. Allain, N. Loubet, L. Pham-Nguyen, E. Deloffre, M. Gros-Jean, R. Beneyton, C. Laviron, M. Marin, C. Leyris, S. Haendler, F. Leverd, P. Gouraud, P. Scheiblin, L. Clement, R. Pantel, S. Deleonibus, and T. Skotnicki, "FDSOI devices with thin BOX and ground plane integration for $32 \mathrm{~nm}$ node and below," Solid State Electron., vol. 53, no. 7, pp. 730734, Jul. 2009.

[5] T.-J. K. Liu, C. Shin, M. H. Cho, X. Sun, B. Nikolić, and B.-Y. Nguyen, "SRAM cell design considerations for SOI technology," in Proc. IEEE Int. SOI Conf., Oct. 2009, pp. 1-4.

[6] C. Shin, M. H. Cho, Y. Tsukamoto, B.-Y. Nguyen, B. Nikoli, and T.-J. K. Liu, "SRAM yield enhancement with thin-BOX FD-SOI," in Proc. IEEE Int. SOI Conf., Oct. 2009, pp. 1-2.

[7] Sentaurus User's Manual, Synopsys, Inc., Mountain View, CA, 2009.06, Jun. 2009.

[8] International Technology Roadmap for Semiconductors. [Online]. Available: http://www.itrs.net

[9] A. K. Rashimi and G. A. Armstrong, "Insights into gate-underlap design in double gate based 6-T SRAM cell for low voltage applications," in Proc. IEEE Int. SOI Conf., Oct. 2008, pp. 61-62.

[10] K. Cheng, A. Khakifirooz, P. Kulkarni, S. Kanakasabapathy, S. Schmitz, A. Reznicek, T. Adam, Y. Zhu, J. Li, J. Faltermeier, T. Furukawa, L. F. Edge, B. Haran, S.-C. Seo, P. Jamison, J. Holt, X. Li, R. Loesing, Z. Zhu, R. Johnson, A. Upham, T. Levin, M. Smalley, J. Herman, M. Di, J. Wang, D. Sadana, P. Kozlowski, H. Bu, B. Doris, and J. O’Neill, "Fully depleted extremely thin SOI technology fabricated by a novel integration scheme featuring implant-free, zero-silicon-loss, and faceted raised source/drain," in VLSI Symp. Tech. Dig., Jun. 2009, pp. 212-213.

[11] Y. Taur and T. H. Ning, Fundamentals of Modern VLSI Devices. Cambridge, U.K.: Cambridge Univ. Press, 2006.

[12] E. Seevinck, F. J. List, and J. Lohstroh, "Static-noise margin analysis of MOS SRAM cells," IEEE J. Solid-State Circuits, vol. SSC-22, no. 5, pp. 748-754, Oct. 1987.

[13] C. Wann, R. Wong, D. J. Frank, R. Mann, S.-B. Ko, P. Croce, D. Lea, D. Hoyniak, Y.-M. Lee, J. Toomey, M. Weybright, and J. Sudijono, "SRAM cell design for stability methodology," in Proc. IEEE VLSI-TSA Int. Symp. VLSI Technol., Apr. 2005, pp. 21-22.

[14] E. Grossar, M. Stucchi, K. Maex, and W. Dehaene, "Read stability and write-ability analysis of SRAM cells for nanometer technologies," IEEE J. Solid-State Circuits, vol. 41, no. 11, pp. 2577-2588, Nov. 2006.

[15] H. Dadgour, K. Endo, V. De, and K. Banerjee, "Modeling and analysis of grain-orientation effects in emerging metal-gate devices and implications for SRAM reliability," in IEDM Tech. Dig., Dec. 2008, pp. 705-708.

[16] A. Cathignol, B. Cheng, D. Chanemougame, A. R. Brown, K. Rochereau, G. Ghibaudo, and A. Asenov, "Quantitative evaluation of statistical variability sources in a 45-nm technological node LP N-MOSFET," IEEE Electron Device Lett., vol. 29, no. 6, pp. 609-611, Jun. 2008.

[17] H. S. Yang, R. Wong, R. Hasumi, Y. Gao, N. S. Kim, D. H. Lee, S. Badrudduza, D. Nair, M. Ostermayr, H. Kang, H. Zhuang, J. Li, L. Kang, X. Chen, A. Thean, F. Arnaud, L. Zhuang, C. Schiller, D. P. Sun, Y. W. Teh, J. Wallner, Y. Takasu, K. Stein, S. Samavedam, D. Jaeger, C. V. Baiocco, M. Sherony, M. Khare, C. Lage, J. Pape, J. Sudijono, A. L. Steegen, and S. Stiffler, "Scaling of $32 \mathrm{~nm}$ low power SRAM with high-K metal gate," in IEDM Tech. Dig., 2008, pp. 233-236.

[18] H. Kawasaki, M. Khater, M. Guillorn, N. Fuller, J. Chang, S. Kanakasabapathy, L. Chang, R. Muralidhar, K. Babich, Q. Yang, J. Ott, D. Klaus, E. Kratschmer, E. Sikorski, R. Miller, R. Viswanathan, Y. Zhang, J. Silverman, Q. Ouyang, A. Yagishita, M. Takayanagi, W. Haensch, and K. Ishimaru, "Demonstration of highly scaled FinFET SRAM cells with high-K/metal gate and investigation of characteristic variability for the $32 \mathrm{~nm}$ node and beyond," in IEDM Tech. Dig., 2008, pp. $237-240$.

[19] B. S. Haran, A. Kumar, L. Adam, J. Chang, V. Basker, S. Kanakasabapathy, D. Horak, S. Fan, J. Chen, J. Faltermeier, S. Seo, M. Burkhardt, S. Burns, S. Halle, S. Holmes, R. Johnson, 
E. McLellan, T. M. Levin, Y. Zhu, J. Kuss, A. Ebert, J. Cummings, D. Canaperi, S. Paparao, J. Arnold, T. Sparks, C. S. Koay, T. Kanarsky, S. Schmitz, K. Petrillo, R. H. Kim, J. Demarest, L. F. Edge, H. Jagannathan, M. Smalley, N. Berliner, K. Cheng, D. LaTulipe, C. Koburger, S. Mehta, M. Raymond, M. Colburn, T. Spooner, V. Paruchuri, W. Haensch, D. McHerron, and B. Doris, "22 nm technology compatible fully functional $0.1 \mu \mathrm{m}^{2}$ 6T-SRAM cell," in IEDM Tech. Dig., 2008, pp. 625-628.

[20] C. H. Diaz, K. Goto, H. T. Huang, Y. Yasuda, C. P. Tsao, T. T. Chu, W. T. Lu, V. Chang, Y. T. Hou, Y. S. Chao, P. F. Hsu, C. L. Chen, K. C. Lin, J. A. Ng, W. C. Yang, C. H. Chen, Y. H. Peng, C. J. Chen, C. C. Chen, M. H. Yu, L. Y. Yeh, K. S. You, K. S. Chen, K. B. Thei, C. H. Lee, S. H. Yang, J. Y. Cheng, K. Y. Huang, J. J. Liaw, Y. Ku, S. M. Jang, H. Chuang, and M. S. Liang, "32 nm gate-first high-k/metalgate technology for high performance low power applications," in IEDM Tech. Dig., 2008, pp. 629-632.

[21] F. Arnaud, J. Liu, Y. M. Lee, K. Y. Lim, S. Kohler, J. Chen, B. K. Moon, C. W. Lai, M. Lipinski, L. Sang, F. Guarin, C. Hobbs, P. Ferreira, K. Ohuchi, J. Li, H. Zhuang, P. Mora, Q. Zhang, D. R. Nair, D. H. Lee, K. K. Chan, S. Satadru, S. Yang, J. Koshy, W. Hayter, M. Zaleski, D. V. Coolbaugh, H. W. Kim, Y. C. Ee, J. Sudijono, A. Thean, M. Sherony, S. Samavedam, M. Khare, C. Goldberg, and A. Steegen, " $32 \mathrm{~nm}$ general purpose bulk CMOS technology for high performance applications at low voltage," in IEDM Tech. Dig., 2008, pp. 633-636.

[22] A. E. Carlson, "Device and circuit techniques for reducing variation in nanoscale SRAM," Ph.D. dissertation, Univ. California Berkeley, Berkeley, CA, May 2008.

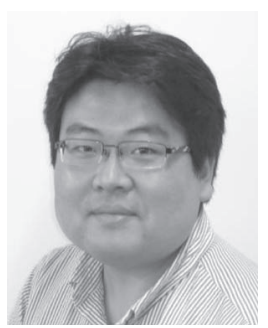

Changhwan Shin (S'04) received the B.S. degree (with top honors) in electrical engineering from Korea University, Seoul, Korea, in 2006. He is currently working toward the Ph.D. degree in electrical engineering in the Department of Electrical Engineering and Computer Sciences, University of California, Berkeley.

In 2004, he received a fellowship from the Korea Foundation for Advanced Studies. His research interests include nonconventional advanced CMOS device designs and their applications to variation-

robust SRAM

Mr. Shin received the General Electric Foundation Scholar-Leaders Award in 2005 and the Best Paper Award and the Best Student Paper Award at the 2009 IEEE International SOI Conference.

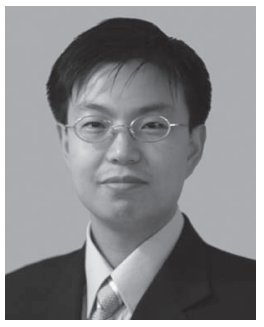

Min Hee Cho received the B.S. degree (with top honors) in metallurgical engineering from Yonsei University, Seoul, Korea, in 1998, and the M.S. degrees in materials science and engineering from the Korea Advanced Institute of Science and Technology, Daejeon, Korea, in 2000. He is currently working toward the Ph.D. degree in electrical engineering in the Department of Electrical Engineering and Computer Sciences, University of California, Berkeley.

From 2000 to 2007, he was with Samsung Electronics as an Engineer, working on process integration of DRAM. He was involved in the development of 512-Mb, 1-G, and 2-G DRAM integration using 88,80 , and $68 \mathrm{~nm}$ technology nodes, respectively. He was also one of the main members to develop recess channel array transistor in DRAM. He is the author or a coauthor of 19 papers. He is the holder of 11 U.S. patents and 27 Korean patents. His current research interests include capacitorless DRAM, FD-SOI transistors, and tunneling transistor simulation.

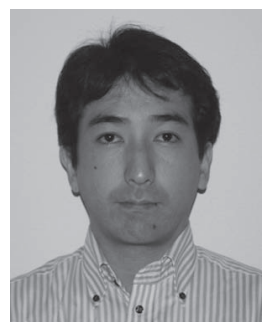

Yasumasa Tsukamoto received the B.S., M.S., and Ph.D. degrees in applied physics from Osaka University, Osaka, Japan, in 1996, 1998 and 2001, respectively.

He joined Mitsubishi Electric Corporation after his graduation and was transferred to Renesas Technology Corporation in 2003. He has been engaged in the development of embedded SRAM design using $90 \mathrm{~nm}, 65 \mathrm{~nm}$ and $45 \mathrm{~nm}$ CMOS logic processes. Since October 2008, he has been with the Department of Electrical Engineering and Computer Sciences, University of California, Berkeley as a Visiting Industrial Fellow, where he is conducting research on state-of-the-art SRAM. His current research interests include variability and reliability issues on SRAM, as well as the application of nonconventional CMOS device technology to the SRAM cell design.

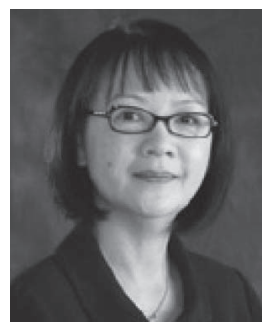

Bich-Yen Nguyen received the B.S. ChE. degree from the University of Texas.

She joined Soitec as a Senior Fellow representing Soitec's R\&D and supporting the development of new fields and applications for Soitec's core technologies. She is also responsible for Soitec's U.S. R\&D projects. Prior to joining Soitec, she was a Senior Manager at Freescale Semiconductor and a Freescale/Motorola Dan Noble Fellow. She has been recognized for her leadership and research in developing Freescale/Motorola's CMOS technology for advanced integrated circuit products. She was also instrumental in transferring process technology to production since 1980, which resulted in a competitive market entry position for Freescale/Motorola. She is the author of more than 150 technical papers on IC process, integration, and device technologies. She is the holder of over 130 worldwide patents.

Ms. Nguyen received the Distinguished Innovation Award in 1991, the Motorola Science Advisory Board Associate in 1992, the Dan Noble Fellow in 2001, which is the highest technical award in Motorola, and the Master of Innovation Award in 2003. In 2004, she received the "Women in Technology Lifetime Achievement Award," which was her first national award. She gave several invited talks, panel discussions, and keynote speeches at major international conferences and universities. She also served as a Committee Member of the IEEE International Electron Devices Meeting, the IEEE Semiconductor Interface Specialists Conference, and the Electrochemical Society Conference and currently serves as a Steering and Technical Committee Member of the International Conference on Integrated Circuit Design and Technology.

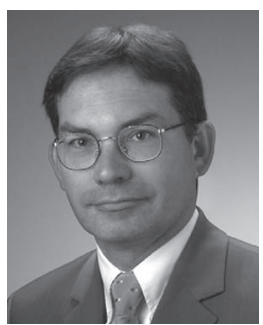

Carlos Mazuré received the Ph.D. degree in physics from the University of Grenoble, Grenoble, France, and from the Technical University of Munich, Munich, Germany.

He joined Soitec in 2001 to create the R\&D organization, which he directed until 2009. He is currently the Chief Technology Officer and Executive Vice President of Soitec, involved in defining Soitec's technology strategy and leads advanced technology alliances with customers and academia. $\mathrm{He}$ focuses on assessing the device-substrate system and in the understanding of the advantages that SOI and engineered substrates bring to the device architecture and fabrication. He works closely with R\&D, business units, business development, sales, and customers to help support existing programs and open new applications. Prior to joining Soitec, he was with Infineon Technologies in Munich, Germany, where he headed the ferroelectric FeRAM development program. Later, as Director of Business Development at Infineon, he initiated the Infineon-Toshiba FeRAM Development Alliance. Before moving to Germany, he was with the IBM/Infineon DRAM Development Alliance in East Fishkill, NY. His experience also includes work on SOI, BiCMOS high-performance SRAM and technology development at APRDL, Motorola Semiconductor in Austin, TX. He is the author or a coauthor of more than 150 technical papers. He is the holder of more than 90 patents worldwide.

Dr. Mazuré is a member of several international technology and advisory committees and is a regular invited speaker at international conferences and workshops. 


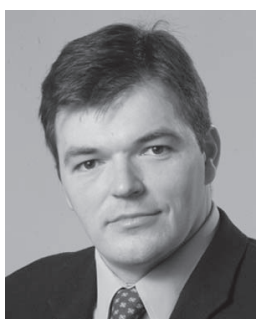

Borivoje Nikolić (S'93-M'99-SM'05) received the Dipl.Ing. and M.Sc. degrees in electrical engineering from the University of Belgrade, Belgrade, Serbia, in 1992 and 1994, respectively, and the Ph.D. degree from the University of California, Davis, in 1999.

He lectured electronics courses at the University of Belgrade from 1992 to 1996 . He spent two years with the Texas Instruments Storage Products Group, Silicon Systems, Inc., San Jose, CA, working on disk-drive signal processing electronics. In 1999, he joined the Department of Electrical Engineering and Computer Sciences, University of California, Berkeley, where he is currently a Professor. His research activities include digital and analog integrated circuit design and VLSI implementation of communications and signal processing algorithms. He is a coauthor of the book Digital Integrated Circuits: A Design Perspective, 2nd ed. (Prentice-Hall, 2003).

Dr. Nikolić received the National Science Foundation CAREER Award in 2003, the College of Engineering Best Doctoral Dissertation Prize and the Anil K. Jain Prize for the Best Doctoral Dissertation in Electrical and Computer Engineering from the University of California, Davis, in 1999, as well as the City of Belgrade Award for the Best Diploma Thesis in 1992. For work with his students and his colleagues, he has received the Best Paper Awards at the IEEE International Solid-State Circuits Conference, the Symposium on VLSI Circuits, the IEEE International SOI Conference and the ACM/IEEE International Symposium of Low-Power Electronics.

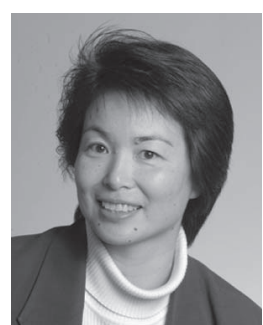

Tsu-Jae King Liu (SM'00-F'07) received the B.S., M.S., and Ph.D. degrees in electrical engineering from Stanford University, Stanford, CA, in 1984, 1986, and 1994, respectively.

In 1992, she joined the Xerox Palo Alto Research Center, Palo Alto, CA, as a Member of Research Staff to research and develop polycrystallinesilicon thin-film transistor technologies for highperformance flat-panel displays. In August 1996, she joined the faculty of the University of California, Berkeley, where she is currently the Conexant Systems Distinguished Professor of Electrical Engineering and Computer Sciences and Associate Dean for Research in the College of Engineering. Her research interests include nanometer-scale integrated-circuit devices and technology, as well as materials, processes, and devices for integrated microsystems.

Dr. Liu received the Defense Advanced Research Projects Agency Significant Technical Achievement Award in 2000 for the development of the FinFET and the IEEE Kiyo Tomiyasu Award in 2010 for contributions to nanoscale MOS transistors, memory devices, and MEMs devices. She has served on committees for many technical conferences, including the IEEE International Electron Devices Meeting and the Symposium on VLSI Technology. She was an Editor for the IEEE ELECTRON DEVICES LETTERS from 1999 to 2004. 